\title{
On the Impact of Texture and Grain Size on the Pseudoelastic Properties of Polycrystalline Fe-Ni-Co-Al-Ti Alloy
}

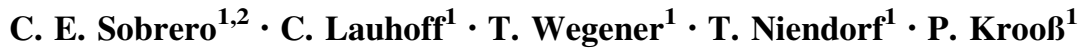

Published online: 8 May 2020

(C) The Author(s) 2020

\begin{abstract}
The effects of thermomechanical treatments on crystallographic texture and grain size evolution and their impact on the pseudoelastic properties in $\mathrm{Fe}_{41}-\mathrm{Ni}_{28}-\mathrm{Co}_{17}-$ $\mathrm{Al}_{11.5}-\mathrm{Ti}_{2.5}$ (at.\%) were studied in the present paper. The results show that cold rolling leads to brass-type texture in this alloy, which is typical for low stacking fault energy materials. Thermal treatments up to $1300{ }^{\circ} \mathrm{C}$ were conducted and it is shown that the presence of $\beta$-phase helps to control grain growth. After the dissolution of the secondary phase induced by heat treatment at higher temperatures, a strong $\{230\}\langle 001\rangle$ recrystallization texture evolves in cold rolled samples already upon imposing medium reduction ratios. Finally, good pseudoelastic properties are found in conditions being characterized by adequate texture and grain sizes spanning over the entire thickness of the samples tested.
\end{abstract}

Keywords Fe-based SMA · Texture · Cold rolling · Superelasticity - Thermomechanical treatment . Recrystallization

This invited article is part of a special issue of Shape Memory and Superelasticity to honor Prof. Dr.-Ing. Gunther Eggeler. This special issue was organized by Prof. Hüseyin Sehitoglu, University of Illinois at Urbana-Champaign, and Prof. Dr.-Ing. Hans Jürgen Maier, Leibniz Universität Hannover.

\section{T. Niendorf}

niendorf@uni-kassel.de

1 Institute of Materials Engineering, University of Kassel, Kassel, Germany

2 Institute of Physics Rosario, CONICET-Universidad Nacional de Rosario, Rosario, Argentina

\section{Introduction}

Shape memory alloys (SMAs) have gained increasing attention due to their unique properties, i.e. shape memory effect and pseudoelasticity (PE) [1]. Among numerous SMA systems, binary $\mathrm{Ni}-\mathrm{Ti}$ is currently the most widely studied alloy system [2,3]. Furthermore, Ni-Ti is used in industrial applications since decades. However, high costs related to complex processing and alloying elements limit its use to niche applications. Thus, due to their low cost and excellent cold workability the development of Fe-based SMAs came into focus of research during the past two decades [1]. However, the inherently non-thermoelastic character of the martensitic transformation (MT) in ferrous SMAs, e.g. Fe-Mn and $\mathrm{Fe}-\mathrm{Mn}-\mathrm{Si}$, has been a roadblock towards obtaining adequate PE behavior $[4,5]$.

Recently, two very promising alloy systems in this class of SMAs showing room temperature PE were discovered, $\mathrm{Fe}-\mathrm{Ni}-\mathrm{Co}-\mathrm{Al}-\mathrm{Ta}-\mathrm{B}$ in 2010 [6] and $\mathrm{Fe}-\mathrm{Mn}-\mathrm{Al}-\mathrm{Ni}$ in 2011 [7]. Since then, many research efforts have been made focusing on the $\mathrm{Fe}-\mathrm{Ni}-\mathrm{Co}-\mathrm{Al}-X$ (FNCAX) $(X=\mathrm{Ta}$, $\mathrm{Ti}, \mathrm{Nb})$ and $\mathrm{Fe}-\mathrm{Mn}-\mathrm{Al}-\mathrm{Ni}-X(X=\mathrm{Ti}, \mathrm{Cr}) \mathrm{SMA}$ systems to improve PE in single- and polycrystalline conditions. In case of FNCAX, the functional properties are based on the MT between the disordered parent $\gamma$-(fcc) and the martensitic $\alpha^{\prime}$-phase (bct) [8-12]. In these alloys, secondary phases play a key role in designing mechanical properties. Obtaining a thermoelastic character of the MT in FNCAX is strongly related to the presence of coherent, ordered $\gamma^{\prime}-\left(L 1_{2}\right)$ precipitates of $\mathrm{Ni}_{3} \mathrm{Al}$-type [9]. Due to the formation of coherency stress fields, these fine dispersed precipitates mechanically strengthen the matrix of the parent phase [7, 13]. However, the formation of the $\beta$-NiAl (B2) phase, particularly along grain boundaries, evokes 
pronounced brittleness deteriorating the mechanical properties [14, 15].

In addition to the role of secondary phases, in polycrystalline structures several microstructural characteristics, i.e. grain size, orientation distribution and texture, respectively, have a significant impact on the functional and structural properties of FNCAX SMAs [14, 15]. The relationship between crystal orientation, crystallographic texture and $\mathrm{PE}$ is well understood for $\mathrm{Fe}-\mathrm{Ni}-\mathrm{Co}-\mathrm{Al}-\mathrm{Ta}(-$ B) $[6,9], \mathrm{Fe}-\mathrm{Ni}-\mathrm{Co}-\mathrm{Al}-\mathrm{Nb}(-\mathrm{B})$ [16] and other alloys belonging to the FNCAX family [13, 14, 17]. For the polycrystalline FNCAX SMAs, all of them containing Boron as an element suppressing the evolution of the $\beta$ phase, cold rolling followed by recrystallization is a wellestablished approach to obtain an excellent PE response in the polycrystalline condition [7]. However, to obtain an appropriate recrystallization texture, i.e. $\{\mathrm{hkl}\}\langle 100\rangle$ in the $\gamma$-phase, crucially needed for superior functional performance, the deformation degree during cold rolling is an important factor. Many studies have confirmed that a cold rolling reduction above $98 \%$ should be achieved to robustly promote $\{\mathrm{hkl}\}\langle 100\rangle$ recrystallization textures $[1,12,17,18]$. Nevertheless, Lee et al. [17] found that PE could already be obtained in thicker sheets, i.e. following a reduction of $90 \%$ only during cold rolling.

In light of these findings, in the present work the influence of various reduction ratios during cold rolling ranging from $85 \%$ to $92 \%$ as well as post-process heat treatments on recrystallization texture and grain size evolution in $\mathrm{Fe}-\mathrm{Ni}$-Co-Al-Ti SMA (without any addition of Boron) has been studied. Incremental strain tests have been conducted at room temperature to study the functional properties under pseudoelastic loading. Results obtained are used to establish solid relationships between the functional properties following thermomechanical processing and related texture evolution as well as the influence of $\beta$ phase in grain growth control.

\section{Experimental Procedure}

A polycrystalline $\mathrm{Fe}_{41}-\mathrm{Ni}_{28}-\mathrm{Co}_{17}-\mathrm{Al}_{11.5}-\mathrm{Ti}_{2.5}$ (at.\%) SMA produced using vacuum induction melting was investigated in this study. Specimens with $20 \mathrm{~mm}$ thickness were cut from the cylindrical as-cast ingots and homogenized at $1150{ }^{\circ} \mathrm{C}$ for $4 \mathrm{~h}$ under argon flow followed by water quenching. Specimens were cold rolled without intermediate annealing with different reduction ratios, i.e. $85 \%$, $90 \%$ and $92 \%$ (85, 90 and 92 in the reminder of the text) leading to final sheet thicknesses of $1.4 \mathrm{~mm}, 0.9 \mathrm{~mm}$ and $0.8 \mathrm{~mm}$, respectively. For microstructure analysis and mechanical testing small specimens as well as dog-boneshaped samples with a gauge length of $18 \mathrm{~mm}$ were electro-discharged machined (EDM) from the cold rolled sheets. To study the impact of recrystallization temperatures on texture and grain size evolution heat treatments were conducted for $0.5 \mathrm{~h}$ at three different maximum temperatures, as highlighted in Fig. 1, followed by water quenching. During the heat treatments samples were kept in quartz tubes under argon atmosphere to avoid oxidation.

For microstructure characterization optical microscopy $(\mathrm{OM})$, scanning electron microscopy (SEM) including electron backscatter diffraction (EBSD) and X-ray diffraction were conducted. Specimens were ground down to $5 \mu \mathrm{m}$ grit size and mechanically polished for $2 \mathrm{~h}$ using a colloidal silica suspension $(0.04 \mu \mathrm{m})$ employing a VibroMet 2 vibratory polishing machine. For OM, specimens were etched using $2 \%$ nitric acid solution. SEM analysis was conducted using Zeiss ULTRA GEMINI high-resolution SEM operated at an accelerating voltage of $20 \mathrm{kV}$. $\mathrm{X}$-ray pole figures and diffractograms were determined using a Seifert Analytical X-ray diffractometer with a Mn tube $(\mathrm{K} \alpha 1 / \mathrm{K} \alpha 2$ lines) and a monochromator at $35 \mathrm{kV}$ and $30 \mathrm{~mA}$. To analyse texture evolution following the different recrystallization treatments (cf. Fig. 1), pole figures from the three main peaks of the $\gamma$-phase were measured and the orientation distribution function (ODF) was calculated using the Mtex Package [19].

In order to evaluate the PE properties, quasi-static uniaxial tensile incremental strain tests (ISTs) were conducted using a servo-hydraulic test rig at ambient temperature. ISTs were carried out at a nominal strain rate of $0.33 \times 10^{-3} \mathrm{~s}^{-1}$ in displacement control. Strains were determined using an extensometer with $12 \mathrm{~mm}$ gauge length. For mechanical testing, samples were additionally aged at $600{ }^{\circ} \mathrm{C}$ for $4 \mathrm{~h}$ to precipitate the $\gamma^{\prime}$-phase. Following aging, samples were again mechanically ground.

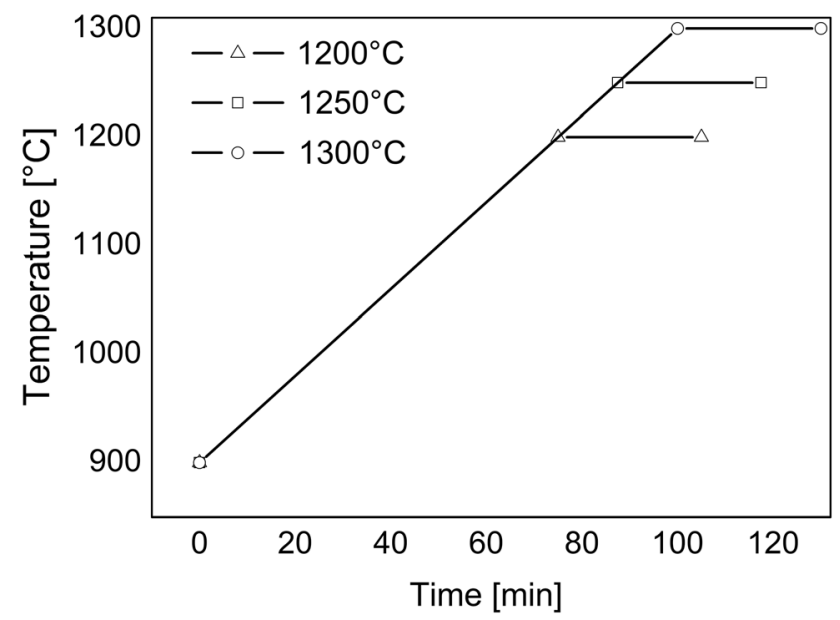

Fig. 1 Thermal treatments conducted in this study with the three different maximum temperatures $1300{ }^{\circ} \mathrm{C}, 1250{ }^{\circ} \mathrm{C}$ and $1200{ }^{\circ} \mathrm{C}$ 


\section{Results and Discussion}

\section{Grain Size and Phase Evolution}

Figure 2 shows the microstructure of $\mathrm{Fe}-\mathrm{Ni}-\mathrm{Co}-\mathrm{Al}-\mathrm{Ti}$ cold rolled material following three different reduction ratios. All conditions are characterized by the presence of $\gamma$ - and $\beta$-phase. As will be highlighted in the following, all measurements conducted in present work using different techniques (X-ray, OM and EBSD) did not reveal the presence of martensite in any specimen following cold rolling. An explanation for this observation could be deduced from the martensite transformation temperatures that are reported to be below $270 \mathrm{~K}$ for several alloys belonging to this family of SMAs. The low transformation temperatures are thought to be responsible for pronounced dislocation activity and the absence of martensitic transformation, however, in-depth analysis is out of the scope of present work. In line with results presented here, however, no martensite after cold rolling was shown in the literature reporting on similar alloys. The $\beta$-phase is oriented alongside the rolling direction (RD) being characterized by elongated grains and the typical "pancake" shape. However, grain morphology of the $\gamma$-phase, i.e. size and shape, as a function of deformation level is not clearly evident from OM analysis. In addition, EBSD inverse pole figure (IPF) maps of the cold rolled specimens were obtained and are displayed in Fig. 3. As can be seen, independent of the deformation degree, grain sizes are in a wide range between $3 \mu \mathrm{m}$ and $10 \mu \mathrm{m}$ due to fragmentation resulting from mechanical processing. The ND plane was chosen for EBSD analysis to facilitate evaluation of grain size evolution. Clearly, intensity of texture increases with increasing reduction ratio. The evolution of the main orientations will be discussed in the next section.

As the microstructures shown are highly unfavorable for enhanced functional performance, thermal treatments (TT) at $1300{ }^{\circ} \mathrm{C}, 1250{ }^{\circ} \mathrm{C}$ and $1200{ }^{\circ} \mathrm{C}$ were performed to study the grain size and texture evolution upon recrystalization. It is important to note that the grain boundary (GB) movement of those GBs that are decorated by secondary phase can be decreased due to pinning forces and, thereby, grain growth is impeded [20]. This phenomenon has been reported for various SMAs, e.g. Cu-based [21], $\mathrm{Co}-\mathrm{Ni}-\mathrm{Ga}$ [22] and FNCAX [12, 17], whereas the $\beta$-phase is present in the latter case. Maximum temperatures of TT were chosen to be close to the dissolution temperature of the $\beta$ phase. For Fe-30Ni-15Co-10Al-2.5Ti-0.05B (at.\%) Lee et al [17]. showed that the alloys are in single $\gamma$-phase condition upon TT at $1200{ }^{\circ} \mathrm{C}$. Figure 4 shows the diffractograms for specimens rolled to $92 \%$ in the as-rolled (Fig. 4i) and recrystallized conditions following TT at $1200{ }^{\circ} \mathrm{C}$, TT at $1250{ }^{\circ} \mathrm{C}$ and TT at $1300{ }^{\circ} \mathrm{C}$ (Fig. 4ii-iv), respectively. As the material is characterized by a similar phase evolution in the as-rolled and heat-treated conditions after cold rolling with reduction ratios of $85 \%$ and $90 \%$, these results are not shown in present work for the sake of brevity. As can be seen in Fig. 4ii), for the $\mathrm{Fe}-\mathrm{Ni}-\mathrm{Co}-\mathrm{Al}-$ Ti SMA being used in the present study $\beta$-phase is still present after cooling from the TT at $1200{ }^{\circ} \mathrm{C}$. However, a significant change in peak intensities of the $\gamma$ - and $\beta$-phase is evident compared to the as-rolled condtion, especially in
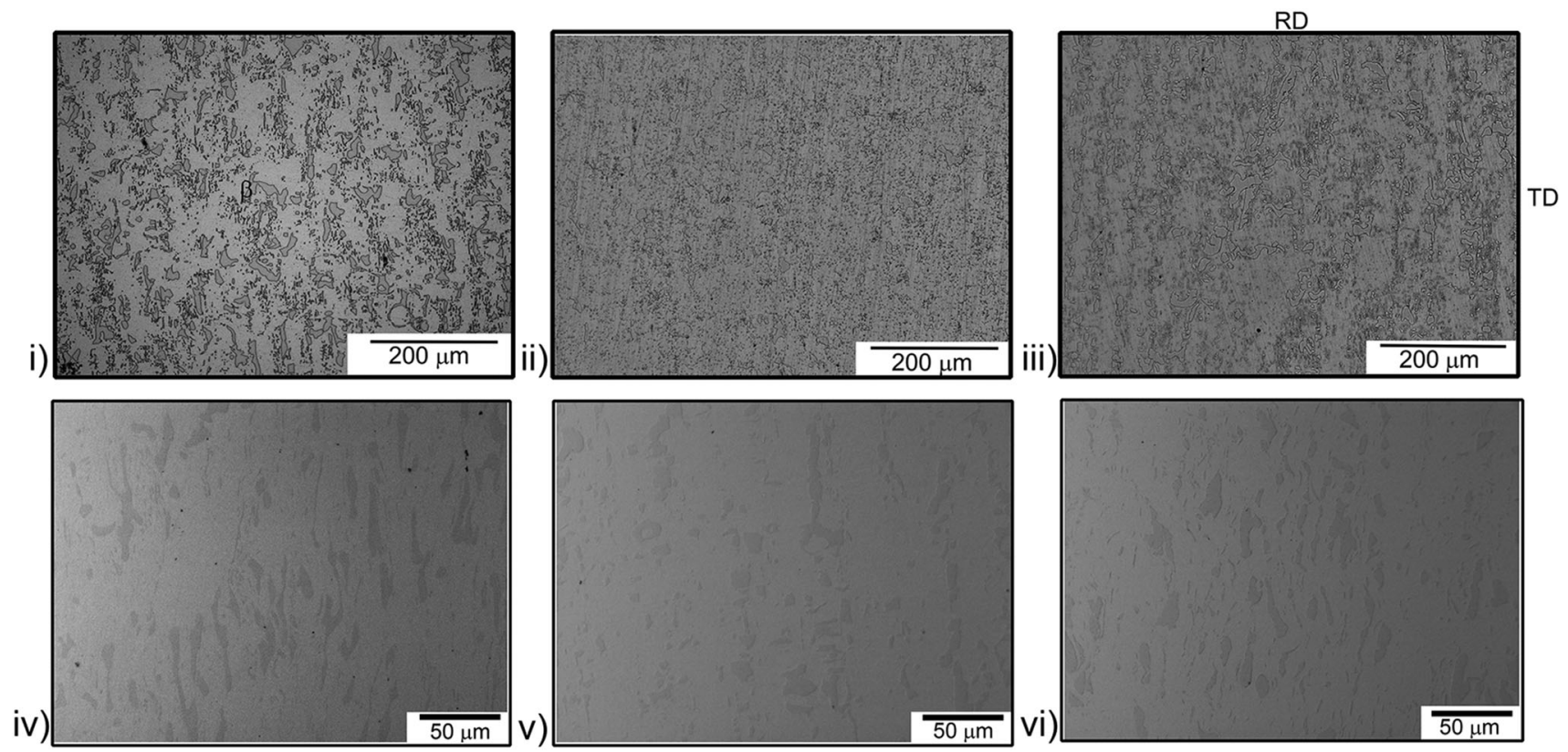

Fig. 2 Optical micrographs of cold rolled specimens with reduction of i, iv $85 \%$; ii, v $90 \%$ and iii, vi $92 \%$ (RD is vertical) 

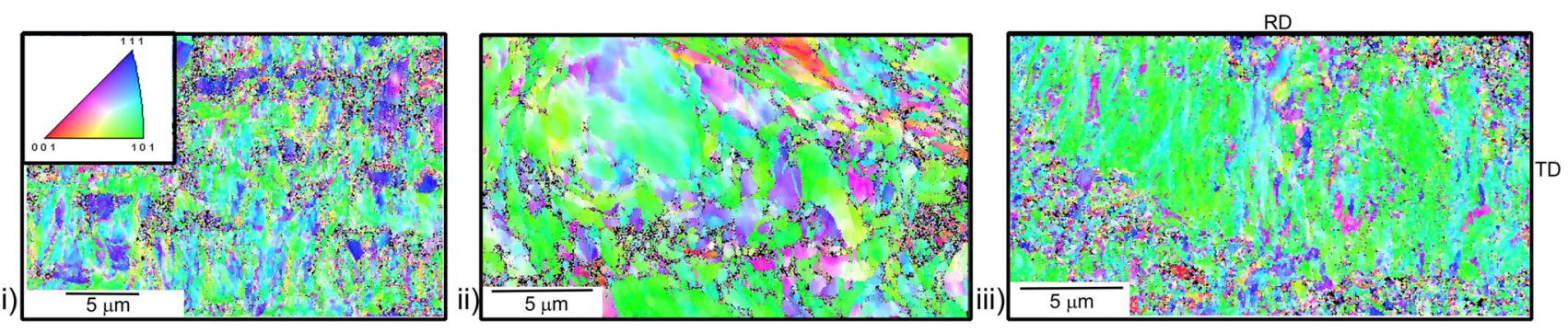

Fig. 3 EBSD inverse pole figure (IPF) maps of cold rolled specimens with reduction ratio of $\mathbf{i} 85 \%$, ii $90 \%$ and iii $92 \%$. The IPF maps were plotted with respect to the normal direction (ND). The color-coded

case of the (220) $\gamma$-peak located at $2 \theta=111^{\circ}$. Thus, according to the diffractogram (Fig. 4ii), the volume fraction of the secondary phase is significantly decreased. Additional analysis using OM (not shown here) revealed values close to $5 \%$. After the TT at $1250{ }^{\circ} \mathrm{C}$ the $\beta$-phase is almost fully dissolved within the matrix, nevertheless, there is still some small amount mostly located at the grain boundaries as can be seen in the 2nd column of Fig. 5 . Upon TT at $1300{ }^{\circ} \mathrm{C}$ no traces of the $\beta$-phase are left. This clearly indicates that the absence of Boron leads to a slight
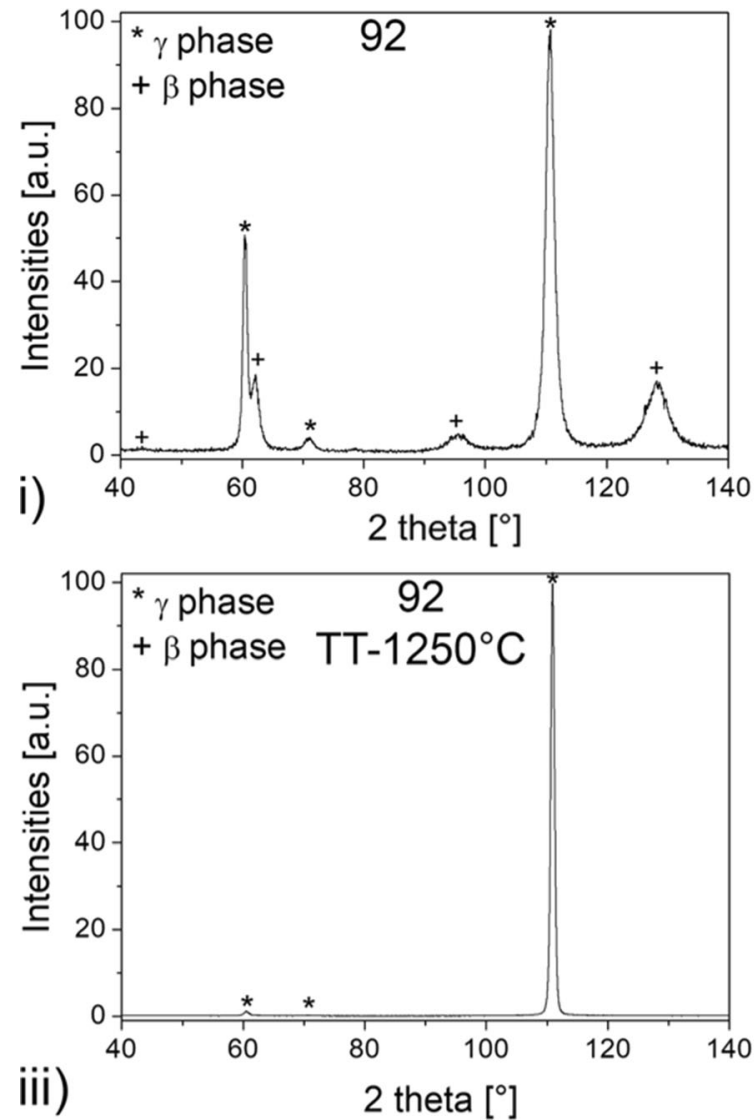

standard triangle and the reference coordinate system are shown in (i) and (iii), respectively (RD is vertical) (Color figure online)

increase of dissolution temperature for the composition investigated in this study.

When the $\beta$-phase is dissolved into the matrix, pinning forces that imped grain growth of the $\gamma$-phase are diminished [17]. Figure 5 shows EBSD IPF maps for the 85, 90 and 92 specimens in the thermally treated conditions. Independent of the reduction ratio during cold rolling, the EBSD plots illustrate an increase in grain size with increasing annealing temperature. In line with the findings obtained by X-ray diffraction, following the TT at $1200{ }^{\circ} \mathrm{C}$ the presence of $\beta$-phase is visible and exemplarily marked
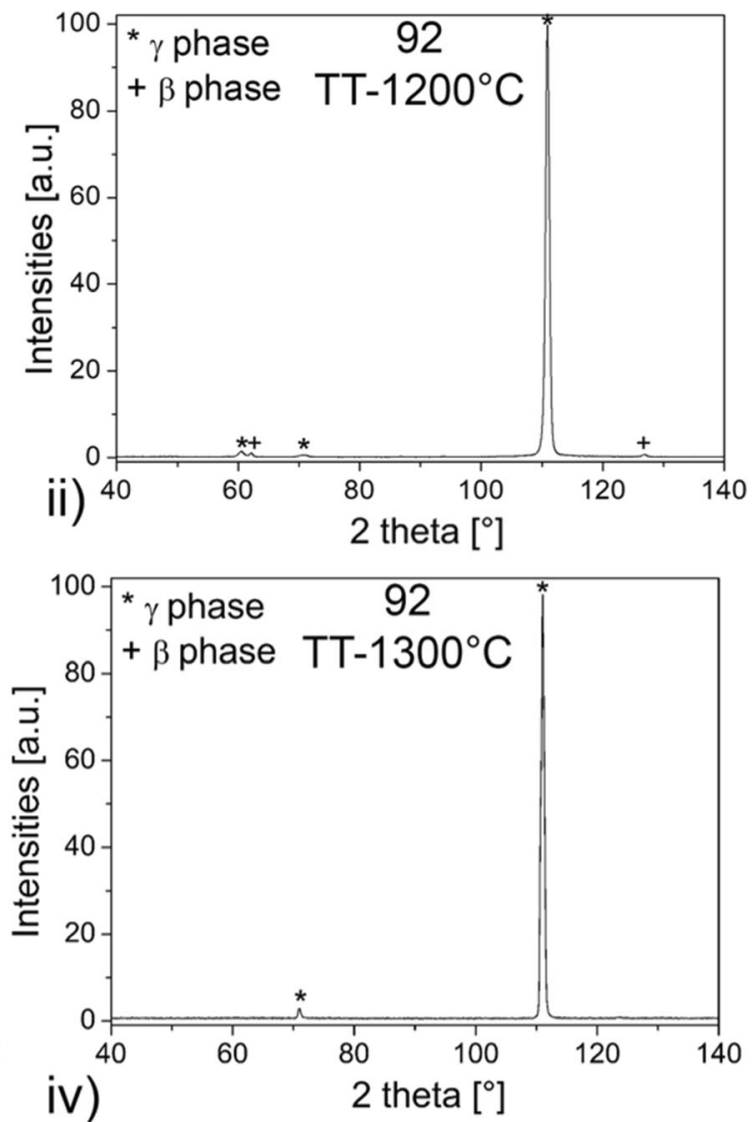

Fig. 4 X-ray diffractograms of specimens rolled with a reduction ratio of $92 \%$ in different conditions: i cold rolled, ii TT- $1200{ }^{\circ} \mathrm{C}$, iii $\mathrm{TT}$ $1250{ }^{\circ} \mathrm{C}$ and iv $\mathrm{TT}-1300{ }^{\circ} \mathrm{C}$ 
by a black arrow (1st column of Fig. 5), whereas only small amounts of $\beta$-phase remain in the microstructure after the TT at $1250{ }^{\circ} \mathrm{C}$ (2nd column of Fig. 5). Finally, following the TT at $1300{ }^{\circ} \mathrm{C}$ (3rd column of Fig. 5) the $\beta$ phase is completely dissolved promoting secondary recrystallization of the $\gamma$-phase leading to grain sizes up to $5 \mathrm{~mm}$. In conclusion, by an appropriate choice of the annealing temperatures and time, grain growth can be robustly applied for adjusting mechanical properties of the FNCAX SMA.

\section{Texture Evolution}

Figure 6 shows ODF sections for $\varphi 2=0^{\circ}, 45^{\circ}$ and $65^{\circ}$ related to the $\gamma$-phase for the 85,90 and 92 specimens in the as-rolled condition. It is known from literature that fcc materials can feature different types of rolling textures, depending on material and processing parameters as well as stacking fault energy [23]. One common type of rolling texture is the so-called Brass-type texture. It can be described as a combination of Brass- $\{110\}\langle 112\rangle$ and Goss$\{110\}\langle 001\rangle$ orientations along the $\alpha$-fiber, where $\langle 110\rangle$ is parallel to the normal direction (ND) of the rolled sheet [23]. As can be deduced from Figs. 2 and 3 the microstructure of the as-rolled specimens is characterized by the fragmentation of the $\gamma$-grains due to the rolling process. The X-ray analysis in Fig. 6 reveals for all asrolled conditions that the resulting texture is Brass-type, being common for low-SFE materials, e.g. FNCAX SMAs [12]. In Fig. 3 the majority of grains is characterized by the $\langle 110\rangle_{\gamma}$ direction being parallel to the ND direction. This result is in good agreement with the definition of the $\alpha$-fiber. However, for all studied deformation ratios a slight change in orientation density can be observed with increasing reduction ratio from $85 \%$ to $92 \%$. This is associated to the increase of the $\{110\}\langle 115\rangle_{\gamma}$ Goss/Brass (see Fig. 6iii) orientation, which has been previously reported as an intermediate texture that appears previously to the full brass texture in conditions featuring a high reduction ratio [18].

In Fig. 7 ODF sections for the $\gamma$-phase are illustrated for specimens heat treated according to TT- $1250{ }^{\circ} \mathrm{C}$. As can be seen in the X-ray diffractogram shown in Fig. 4 and the EBSD images shown in Fig. 5 following the TT at $1250{ }^{\circ} \mathrm{C}$, the $\beta$-phase still is present in the microstructure, particularly alongside the GBs. As previously discussed, the main phase, i.e. the $\gamma$-phase, thus, has not been fully recrystallized. Grain size is around $50 \mu \mathrm{m}$ for a reduction ratio of $85 \%$ and close to $200 \mu \mathrm{m}$ for the reduction ratios of $90 \%$ and $92 \%$ (cf. Fig. 5). In addition, the main texture component remains in the $\alpha$-fiber, however, with a remarkable increase of the Goss/Brass orientation for all
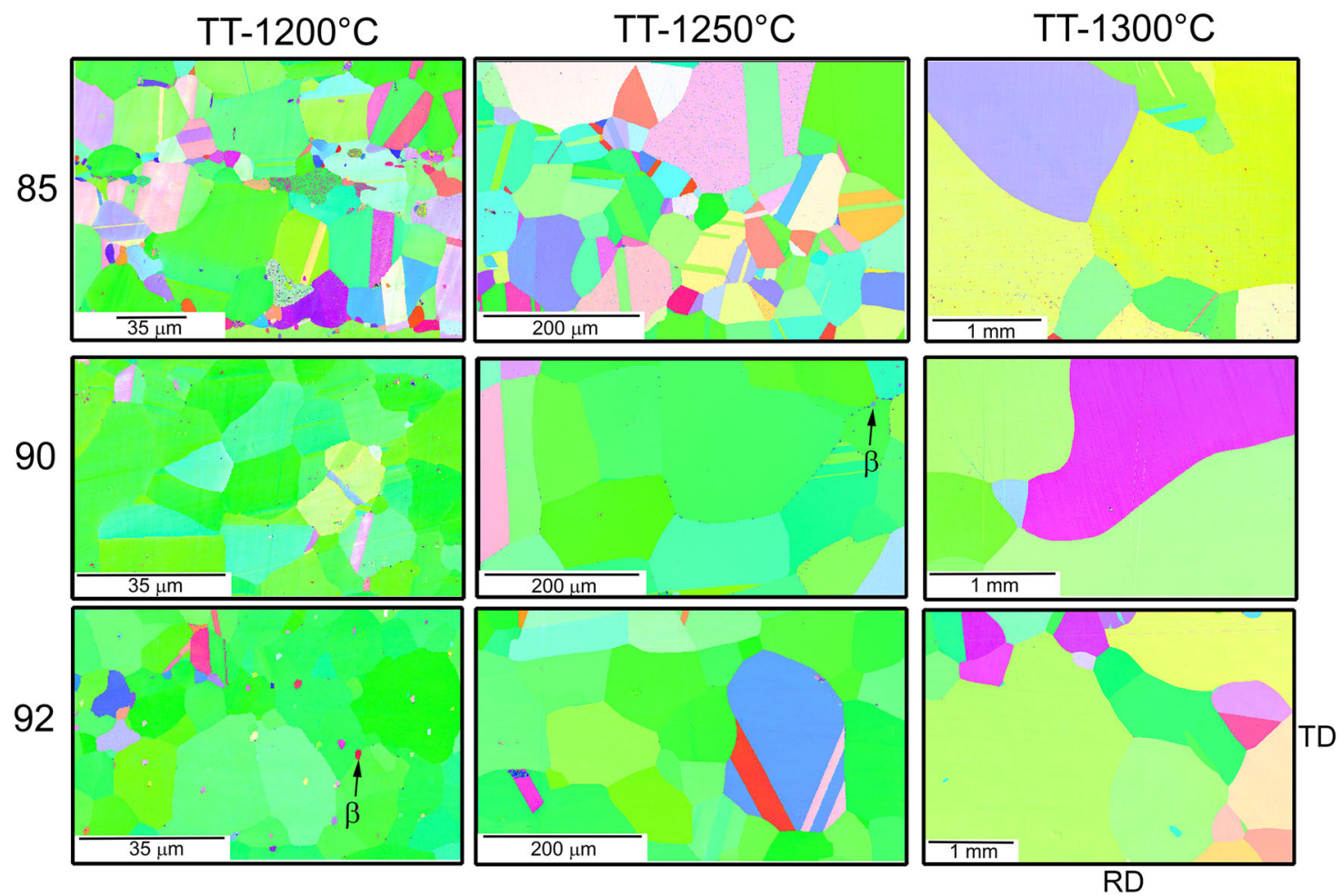

Fig. 5 EBSD IPF maps in the ND plane of all conditions after thermal treatments. The color-coded standard triangle and the reference coordinate system are shown in Fig. 3. RD is vertical. Scale bars are different for the conditions considered (Color figure online) 

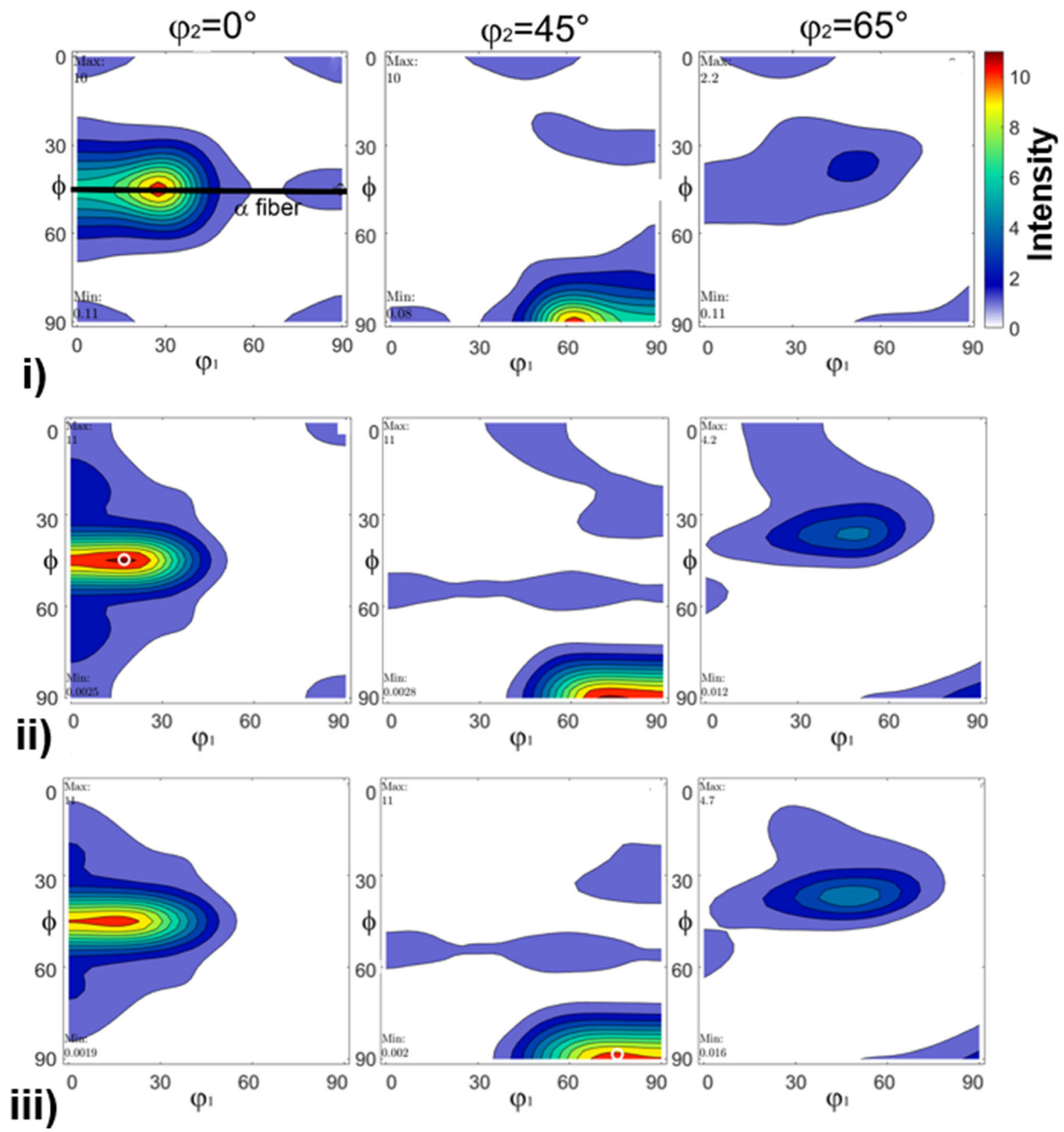

Fig. 6 ODF sections for $\varphi 2=0^{\circ}, 45^{\circ}$ and $65^{\circ}$ for cold rolled specimens with reduction ratios of i $85 \%$, ii $90 \%$ and iii $92 \%$. (Orientation $\{110\}\langle 115\rangle \gamma$ is marked with ${ }^{\circ}$ in iii) (Color figure online)

TT- $1250{ }^{\circ} \mathrm{C}$ specimens. The significant increase of the ODF density intensities is also reflected in the remarkable change of the $(220)_{\gamma}$ peak between the as-rolled and subsequently heat-treated condition shown in the diffractograms in Fig. 4i and iii, respectively. Furthermore, grain sizes and the intensity of the main orientation increase with increasing reduction ratio (cf. 2nd column in Figs. 5 and 7). This is related to the stored energy imposed by the deformation process of the material. Texture evolution during the TT at $1200{ }^{\circ} \mathrm{C}$ is very similar and, thus, not shown in the present paper for the sake of brevity.
Figure 8 shows the ODFs for specimens heat treated according to the TT- $1300{ }^{\circ} \mathrm{C}$. Annealing at this temperature results in the full dissolution of the $\beta$-phase (cf. Fig. 4iv and the 3rd column of Fig. 5). Due to the absence of the secondary phase, there is no pinning force that could impede the secondary recrystallization and, thus, grains grow up to $5 \mathrm{~mm}$ as can be seen in Fig. 5. In addition, a fundamental change of the texture component occurs during the recrystallization process at $1300{ }^{\circ} \mathrm{C}$ as compared to microstructure evolution upon TT at $1200{ }^{\circ} \mathrm{C}$ and TT at $1250{ }^{\circ} \mathrm{C}$. In detail, the $\alpha$-fiber vanishes and is replaced by the $\{\mathrm{hkl}\}\langle 100\rangle_{\gamma}$ type component, where the $\langle 100\rangle$ direction 


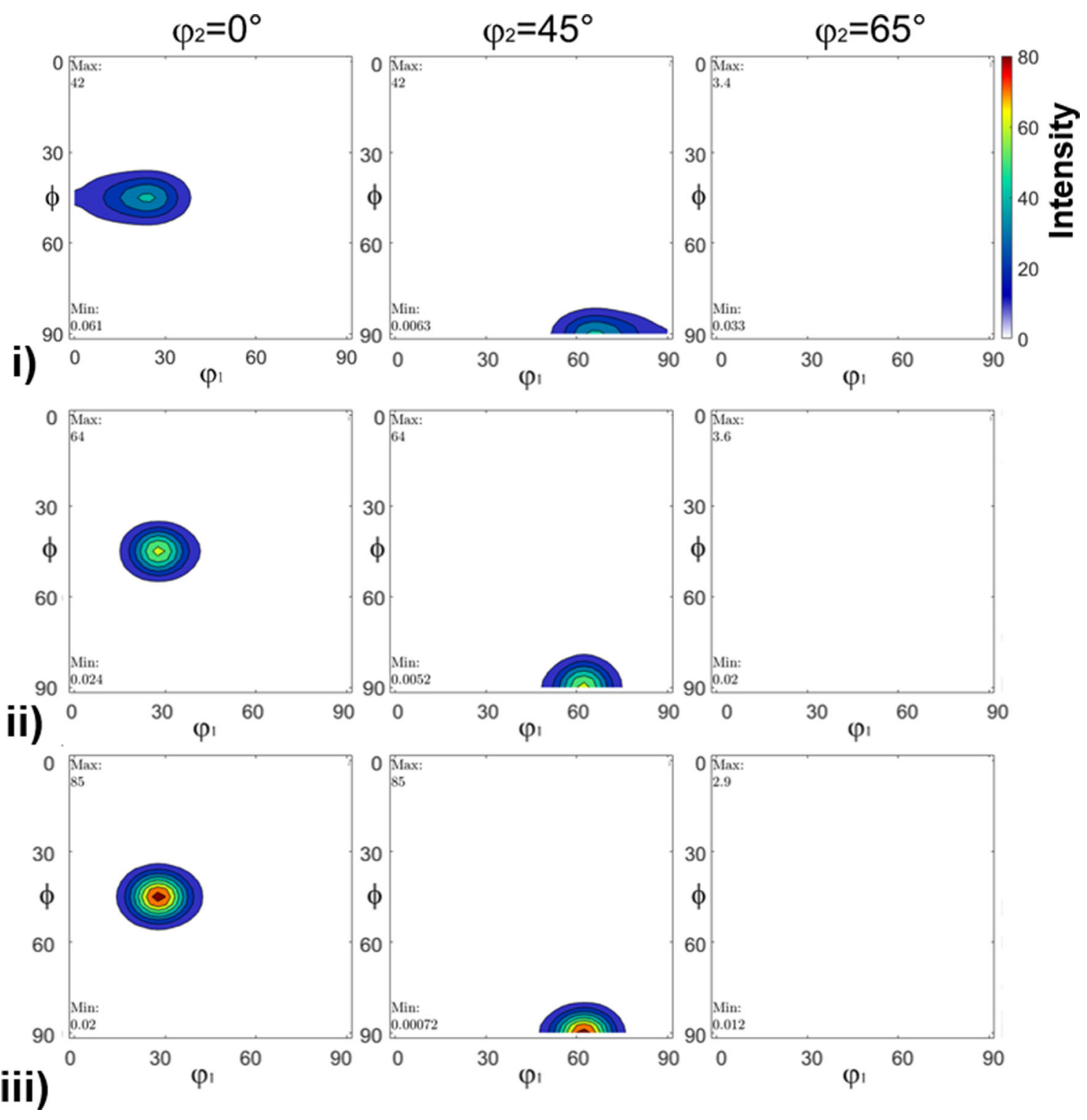

Fig. 7 ODF sections for $\varphi 2=0^{\circ}, 45^{\circ}$ and $65^{\circ}$ for specimens heat treated according to TT $-1250{ }^{\circ} \mathrm{C}$ subsequent to cold rolling with reduction ratios of i $85 \%$, ii $90 \%$ and iii $92 \%$ (Color figure online)

is parallel to RD. For the specimen being characterized by a reduction ratio of $92 \%$, the texture main component is Goss- $\{110\}\langle 001\rangle_{\gamma}$, whereas for both 85 and 90 specimens the main component is close to $\{230\}\langle 001\rangle$. This texture evolution is in good agreement with previous results observed by various authors $[12-14,18]$. However, texture intensities reported in this paper are higher than the ones obtained in previous works when looking at similar reduction ratios. This difference might, at least in part, result from the relative slow heating to the maximum temperature during the TT allowing for well-defined development of recrystallized grains in the material.

\section{Pseudoelasticity}

Samples treated according to TT- $1250{ }^{\circ} \mathrm{C}$ and TT- $1300{ }^{\circ} \mathrm{C}$ were aged at $600{ }^{\circ} \mathrm{C}$ for $4 \mathrm{~h}$ to induce $\gamma^{\prime}$-phase precipitates. Besides the influence of texture, the size and the volume fraction of the $\gamma^{\prime}$-phase play an important role in phase transformation as both affect the morphology of the martensite and eventually the amount of irreversible deformation following pseudoelastic testing [9, 13]. Figure 9 shows the pseudoelastic response at room temperature for the specimens treated according to TT- $1250{ }^{\circ} \mathrm{C}$ and TT- $1300{ }^{\circ} \mathrm{C}$ (RD is parallel to load direction). As can be seen in Fig. 9v, the transformation stress is close to $500 \mathrm{MPa}$ and a fully reversible MT is obtained for the 


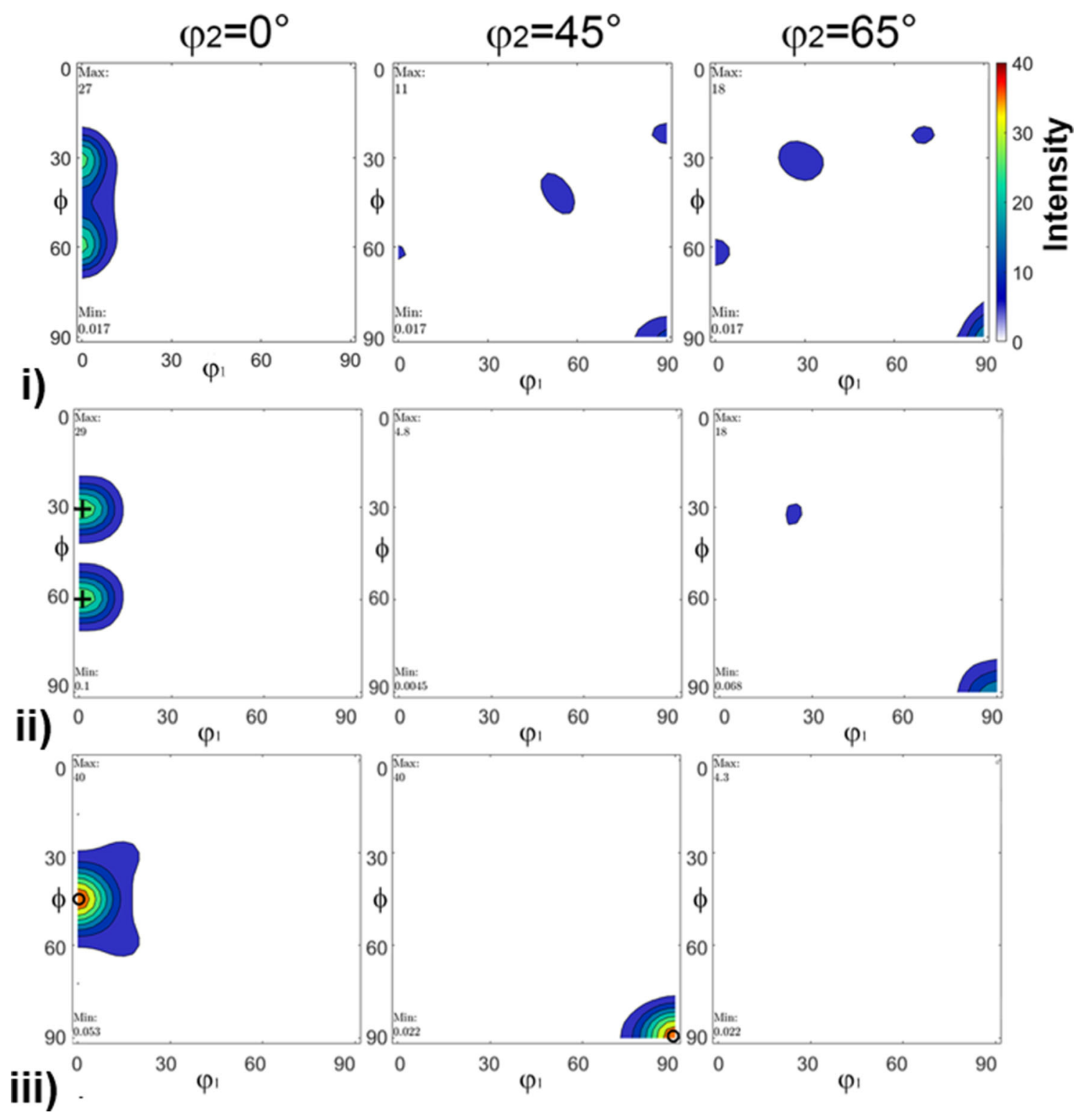

Fig. 8 ODF sections for $\varphi 2=0^{\circ}, 45^{\circ}$ and $65^{\circ}$ for specimens heat-treated according to TT- $1300{ }^{\circ} \mathrm{C}$ following cold rolling with reduction ratios of $\mathbf{i} 85 \%$, ii $90 \%$ and iii $92 \%$. ( $\{230\}\langle 001\rangle$ is marked with + in ii and Goss Orientation is marked with ${ }^{\circ}$ in iii) (Color figure online)

specimen being characterized by a reduction ratio of $90 \%$ following the TT at $1300{ }^{\circ} \mathrm{C}$. Nevertheless, the specimen failed after $1.5 \%$ of deformation, which could probably be attributed to remaining high angle grain boundaries as was suggested by Lee et al. [17]. These grain boundaries can result in a brittle material behavior and, thus, to early fracture. The EBSD results in Fig. 5 support this assumption, as the microstructure still contains some grains being characterized by unfavorable crystallographic orientation. The 85 and 92 specimens after TT at $1300{ }^{\circ} \mathrm{C}$ show no PE effect upon deformation. The transformation stress for a reduction ratio of $92 \%$ is around $800 \mathrm{MPa}$ and the sample with the reduction ratio of $85 \%$ already failed in the elastic regime. The difference in mechanical response can be related to grain constraints being present due to grains lacking adequate crystallographic orientation. Since the aging treatments were done in the same way throughout all tests, aging affected changes in the mechanical response can be excluded. So far, data reported in the literature revealed that only very specific material conditions are characterized by good PE properties in case of the FNCAX SMAs. Only thermomechanically processed conditions being characterized by pronounced texture and grain sizes up to $2 \mathrm{~mm}$, spanning over the entire thickness of the samples, showed a fully reversible phase transformation [17]. This kind of microstructure helps suppressing grain constrains in the sample volume, since every single grain is solely constraint in a $2 \mathrm{D}$ space. Upon $\mathrm{TT}-1300{ }^{\circ} \mathrm{C}$ the grain 

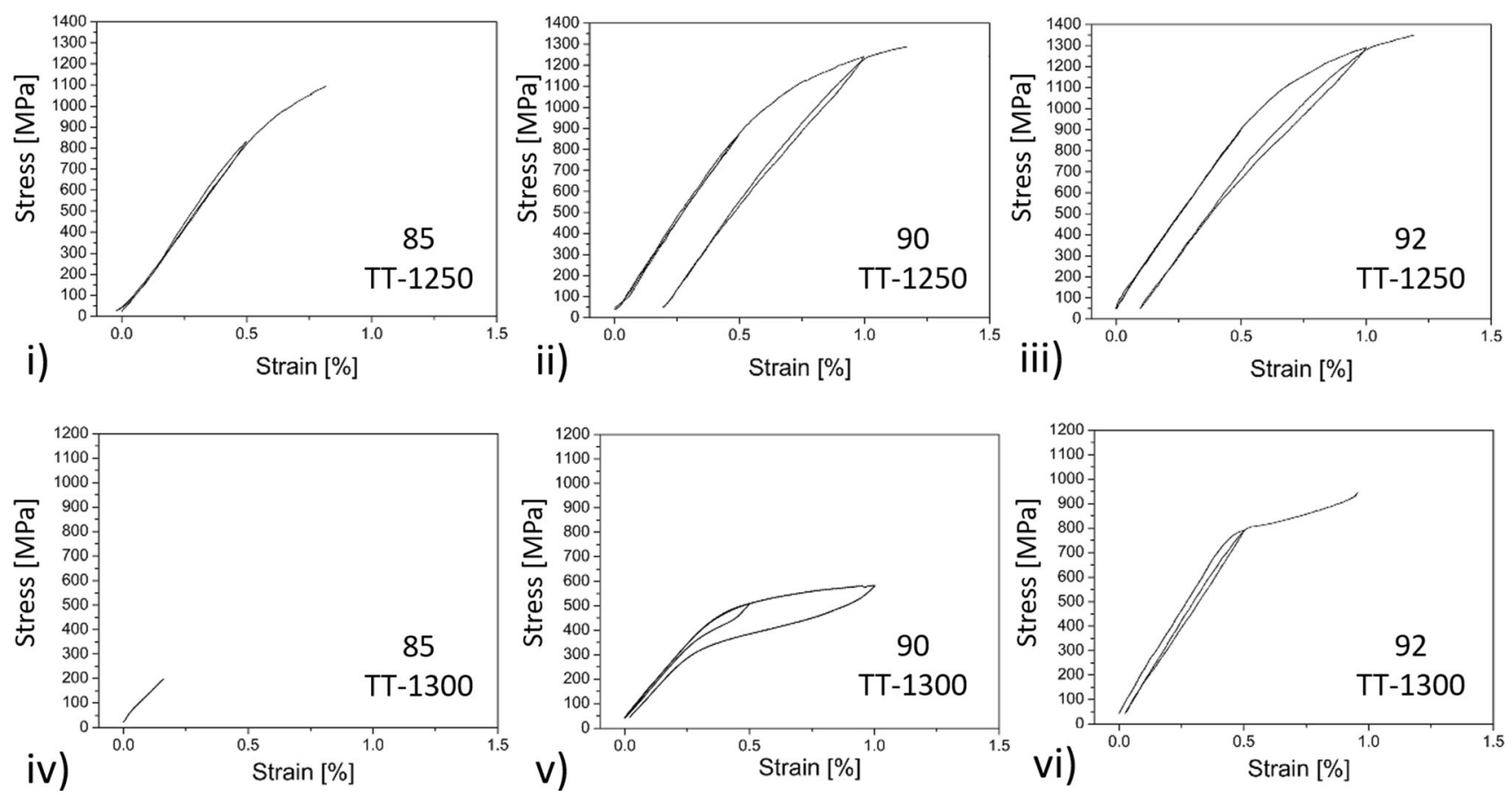

Fig. 9 Pseudoelastic response of specimens upon treatment according to TT-1250 ${ }^{\circ} \mathrm{C}$ (i-iii) and TT-1300 ${ }^{\circ} \mathrm{C}$ (iv-vi) subsequently aged at $600{ }^{\circ} \mathrm{C}$ for $4 \mathrm{~h}$ (RD parallel to load direction)

size grows up to more than $3 \mathrm{~mm}$ and, thus, spans over the entire thickness of the samples tested. In addition, as can be seen on ODF sections in Fig. 8, the texture in specimens changes from $\{230\}\langle 001\rangle$ orientation upon reduction of $85 \%$ and $90 \%$ to Goss in the $92 \%$ condition. The $\{230\}\langle 001\rangle$ was previously reported to be a beneficial texture for PE [12] while there as is no references in the literature reporting on good PE response for pure Goss texture. Finally, the intensities of the main orientations in the $90 \%$ specimens are higher than in $85 \%$. In consequence, only in the TT- $1300{ }^{\circ} \mathrm{C}$ condition (reduction ratio of $90 \%$ ) the grain orientation as well as grain size seem to precisely fulfil the prerequisites for reversible functional properties.

As is revealed in Fig. 5, upon TT at $1250{ }^{\circ} \mathrm{C}$ unfavorable oriented grains may lead to significant grain constraints, however, the fraction of unfavorable grains is lower for $90 / \mathrm{TT}-1250{ }^{\circ} \mathrm{C}$ and $92 / \mathrm{TT}-1250{ }^{\circ} \mathrm{C}$ conditions. This might explain the differences in the mechanical response for the sample featuring a reduction ratio of $85 \%$. In this condition a very early fracture is observed, similar to the $85 / \mathrm{TT}-1300{ }^{\circ} \mathrm{C}$ condition. For both the 90 and 92 specimens following the TT at $1250{ }^{\circ} \mathrm{C}$ at least minor PE behavior is seen. Stresses for MT in these conditions are significantly higher as compared to the TT- $1300{ }^{\circ} \mathrm{C}$ conditions featuring the same reduction ratios. Since the ODF sections of the TT- $1250{ }^{\circ} \mathrm{C}$ conditions reveal a high density of Goss/Brass texture with a majority of $\{110\}$ planes parallel to the ND plane and the $\langle 115\rangle$ directions parallel to rolling direction, a possible explanation for the higher stresses for MT can be deduced. According to [24] the resolved shear stress factor (RSSF) is higher in the $\langle 111\rangle$ direction than in $\langle 001\rangle$. Thus, critical stresses for MT are supposed to be higher for the $\langle 115\rangle$ direction as compared to $\langle 001\rangle$, eventually exceeding the yield strength of the material. A similar behavior was also observed by Kireeva et al. [25], who showed the evolution of critical stresses for differently oriented single crystals in the $\mathrm{Fe}-\mathrm{Ni}-\mathrm{Co}-\mathrm{Al}-\mathrm{Ta}$ SMA system. This clearly provides for a rationale for the low reversibility in this condition. Nevertheless, the high ultimate stresses found are thought to indicate that the TT$1250{ }^{\circ} \mathrm{C}$ conditions can be suitable candidates for excellent functional properties at lower testing temperatures, i.e. taking into account the Clausius-Clapeyron relationship. However, a reliable conclusion is hardly possible at this point, as only limited mechanical data are available for the respective orientation.

\section{Conclusions}

The influence of cold rolling and subsequent thermal treatments on grain size and texture evolution of $\mathrm{Fe}-\mathrm{Ni}-$ Co-Al-Ti SMA (without Boron addition) was studied and the following conclusions could be drawn: 
(1) The dissolution temperature of the secondary $\beta$ phase is close to $1250{ }^{\circ} \mathrm{C}$ for the present composition. Since the $\beta$-phase strongly impedes grain boundary motion during annealing, the presence of the secondary phase allows direct control of grain growth and texture.

(2) Due to full dissolution of the $\beta$-phase upon annealing at $1300{ }^{\circ} \mathrm{C}$, secondary recrystallization of the $\gamma$ parent phase occurs leading to significant grain growth and a major modification in texture components, i.e. a change of character from Brass type to $\{$ hkl $\}\langle 001\rangle$.

(3) X-ray analysis reveals adequate texture evolution already in conditions following medium deformation (reduction ratios below 92\%) and annealing at $1300{ }^{\circ} \mathrm{C}$. This clearly is a significant improvement as compared to results available in the literature stating that a thickness reduction of $98.5 \%$ is required.

(4) Good pseudoelastic performance has been obtained in a condition being characterized by a $\{230\}\langle 001\rangle$ texture after thermal treatment at $1300{ }^{\circ} \mathrm{C}$. This is attributed to favorable grain orientations and grain sizes spanning over the entire thickness of the samples tested, effectively avoiding detrimental grain constraints in the sample volume.

Acknowledgement Open Access funding provided by Projekt DEAL. Financial support by Deutsche Forschungsgemeinschaft (DFG) (Project No. 405372848) is gratefully acknowledged.

Open Access This article is licensed under a Creative Commons Attribution 4.0 International License, which permits use, sharing, adaptation, distribution and reproduction in any medium or format, as long as you give appropriate credit to the original author(s) and the source, provide a link to the Creative Commons licence, and indicate if changes were made. The images or other third party material in this article are included in the article's Creative Commons licence, unless indicated otherwise in a credit line to the material. If material is not included in the article's Creative Commons licence and your intended use is not permitted by statutory regulation or exceeds the permitted use, you will need to obtain permission directly from the copyright holder. To view a copy of this licence, visit http://creativecommons. org/licenses/by/4.0/.

\section{References}

1. Otsuka K, Wayman CM (1998) Shape memory materials. Cambridge University Press, New York

2. Eggeler G, Hornbogen E, Yawny A, Heckmann A, Wagner M (2004) Structural and functional fatigue of NiTi shape memory alloys. Mater Sci Eng A 378:24-33

3. Isola L, La Roca P, Sobrero C, Fuster V, Vermaut Ph, Malarría J (2016) Martensitic transformation strain and stability of Ni50- $\mathrm{x}-$ Ti50-Cox $(x=3,4)$ strips obtained by twin-roll casting and standard processing techniques. Mater Des 107:511-519
4. Druker A, LaRoca P, Vermaut P, Ochin P, Malarria J (2012) Microstructure and shape memory properties of $\mathrm{Fe}-15 \mathrm{Mn}-5 \mathrm{Si}-$ 9Cr-5Ni melt-spun ribbons. Mater Sci Eng A 556:936-945

5. Druker AV, Perotti A, Esquivel I, Malarría J (2014) A manufacturing process for shaft and pipe couplings of $\mathrm{Fe}-\mathrm{Mn}-\mathrm{Si}-\mathrm{Ni}-$ Cr shape memory alloys. Mater Des 56:878-888

6. Tanaka Y, Himuro Y, Kainuma R, Sutou Y, Omori T, Ishida K (2010) Ferrous polycrystalline shape-memory alloy showing huge superelasticity. Science 327:1488-1490

7. Omori T, Ando K, Okano M, Xu X, Tanaka Y, Ohnuma I, Kainuma R, Ishida K (2011) Superelastic effect in polycrystalline ferrous alloys. Science 333:68-71

8. Ma J, Kockar B, Evirgen A, Karaman I, Luo ZP, Chumlyakov YI (2012) Shape memory behavior and tension-compression asymmetry of a FeNiCoAlTa single-crystalline shape memory alloy. Acta Mater 60:2186-2195

9. Krooß P, Somsen C, Niendorf T, Schaper M, Karaman I, Chumlyakov Y, Eggeler G, Maier HJ (2014) Cyclic degradation mechanisms in aged FeNiCoAlTa shape memory single crystals. Acta Mater 79:126-137

10. Abuzaid W, Sehitoglu H (2018) Superelasticity and functional fatigue of single crystalline FeNiCoAlTi iron-based shape memory alloy. Mater Des 160:642-651

11. Omori T, Abe S, Tanaka Y, Lee DY, Ishida K, Kainuma R (2013) Thermoelastic martensitic transformation and superelasticity in $\mathrm{Fe}-\mathrm{Ni}-\mathrm{Co}-\mathrm{Al}-\mathrm{Nb}-\mathrm{B}$ polycrystalline alloy. Scr Mater 69:812-815

12. Fu H, Zhao H, Song S, Zhang Z, Xie J (2016) Evolution of the cold-rolling and recrystallization textures in FeNiCoAlNbB shape memory alloy. J Alloy Compd 686:1008-1016

13. Zhang $\mathrm{C}$, Zhu C, Harrington $\mathrm{T}$, Casalena L, Wang $\mathrm{H}$, Shin $\mathrm{S}$, Vecchio KS (2019) Multifunctional non-equiatomic high entropy alloys with superelastic, high damping, and excellent cryogenic properties. Adv Eng Mater 21:1800941

14. Fu H, Li W, Song S, Jiang Y, Xie J (2016) Effects of grain orientation and precipitates on the superelasticity in directionally solidified FeNiCoAlTaB shape memory alloy. J Alloys Compd 684:556-563

15. Zhang C, Zhu C, Shin S, Casalena L, Vecchio K (2019) Grain boundary precipitation of tantalum and $\mathrm{NiAl}$ in superelastic FeNiCoAlTaB alloy. Mater Sci Eng A 743:372-381

16. Chumlyakov YI, Kireeva IV, Kutz OA, Turabi AS, Karaca HE, Karaman I (2016) Unusual reversible twinning modes and giant superelastic strains in FeNiCoAlNb single crystals. Scr Mater 119:43-46

17. Lee D, Omori T, Han K, Hayakawa Y, Kainuma R (2018) Effect of thermomechanical processing on texture and superelasticity in $\mathrm{Fe}-\mathrm{Ni}-\mathrm{Co}-\mathrm{Al}-\mathrm{Ti}-\mathrm{B}$ alloy. Shape Memory Superelasticity 4:102-111

18. Zhao H, Fu H, Xie J, Zhang Z (2018) Effects of solution treatment on microstructure and superelasticity of FeNiCoAlTaB alloy. Mater Res Express 5:016508

19. Bachmann F, Hielscher R, Schaeben H (2010) Texture analysis with MTEX: free and open source software toolbox. Solid State Phenom 160:63-68

20. Humphreys MHFJ (2004) Recrystallization and related annealing phenomena. Elsevier, Amsterdam

21. Sobrero CE, La Roca P, Roatta A, Bolmaro RE, Malarría J (2012) Shape memory properties of highly textured $\mathrm{Cu}-\mathrm{Al}-\mathrm{Ni}-(\mathrm{Ti})$ alloys. Mater Sci Eng A 536:207-215

22. Niendorf T, Lauhoff C, Karsten E, Gerstein G, Liehr A, Krooß P, Maier HJ (2019) Direct microstructure design by hot extrusion: high-temperature shape memory alloys with bamboo-like microstructure. Scr Mater 162:127-131

23. Leffers T, Ray RK (2009) The brass-type texture and its deviation from the copper-type texture. Prog Mater Sci 54:351-396 
24. Sehitoglu H, Karaman I, Zhang XY, Chumlyakov Y, Maier HJ (2001) Deformation of FeNiCoTi shape memory single crystals. Scr Mater 44:779-784

25. Kireeva IV, Chumlyakov YI, Kirillov VA, Karaman I, Cesari E (2011) Orientation and temperature dependence of superelasticity caused by reversible $\gamma-\alpha^{\prime}$ martensitic transformations in FeNiCoAlTa single crystals: technical. Phys Lett 37:487-490

Publisher's Note Springer Nature remains neutral with regard to jurisdictional claims in published maps and institutional affiliations. 